\title{
Scalp, Skull, Lung and Bone Metastasis from Follicular Thyroid Carcinoma - A Rare Case Report
}

\author{
Gupta $\mathrm{S}^{*}$, Madholia $\mathrm{V}^{2}$, Mukherjee $\mathrm{A}^{2}$ and Bhowmik KT ${ }^{2}$ \\ ${ }^{1}$ Department of Radiotherapy, S.N Medical College, Agra, India \\ ${ }^{2}$ Department of Radiotherapy, Safdarjung Hospital, New Delhi, India
}

${ }^{*}$ Corresponding author: Gupta S, Department of Radiotherapy, S.N Medical College, Agra, India, Tel: 9760025076, E-mail: mttsurabhi@rediffmail.com

Citation: Gupta S, Madholia V, Mukherjee A, Bhowmik KT (2017) Scalp, Skull, Lung and Bone Metastasis from Follicular Thyroid Carcinoma - A Rare Case Report. J Cancer Sci Clin Oncol 4(2): 202. doi: 10.15744/23946520.4.202

Received Date: December 29, 2016 Accepted Date: December 15, 2017 Published Date: December 18, 2017

\begin{abstract}
Concurrent scalp, skull, lung and bone metastasis from follicular thyroid carcinoma is a very rare event. We herein present the case of a 37- year's old lady, who presented to us with huge scalp swelling that proved to be metastasis from a follicular thyroid carcinoma. The metastatic workup disclosed bilateral lung metastasis and additional metastasis in right iliac crest and 6th rib. The course of her disease was relentless. Although follicular thyroid carcinoma has an excellent prognosis, the presence of metastatic disease leads to a very dismal prognosis.
\end{abstract}

Keywords: Thyroid cancer; metastasis; scalp and skull

\section{Introduction}

Thyroid cancer is a relatively uncommon malignancy comprising about $1 \%$ of all malignancies. Follicular thyroid carcinoma accounts for 10-20\% of all thyroid malignancies and it tends to occur more frequently in older patients, over 40 years of age [1]. Follicular cancers are generally solitary, have a marked tendency to invade vascular channels and metastasize hematogenously to distant sites. Lymph node metastases are uncommon. These tumours also have a marked propensity to concentrate I-131. On histopathological examination, these cancers lack papillae, psamomma bodies or ground glass nuclei. At the time of diagnosis of follicular thyroid carcinomas, around $15 \%$ patients are found to have distant metastasis, most commonly in the lung and bone [2] and also occasionally in the skin. We report an unusual case of scalp metastasis from follicular thyroid carcinoma in a young female with formation of a large mass lesion eroding cranial vault with pulmonary and skeletal metastasis.

\section{Case Report}

A 37 years old female presented to us with a large swelling on scalp with history of progressive increase in size of swelling for last 4 years. Patient was in respiratory distress and having severe pain over the right thigh. Patient had not taken any treatment for previous 4 years. On clinical examination there was a huge swelling of the scalp, of size greater than that of head with increased vascularity of the base of swelling. Patient was unable to sit down due to huge skull mass. There was tenderness over the right iliac region. A hard nodule of size $2 \mathrm{X} 3 \mathrm{~cm}$ was also noticed at the base of scalp swelling. Fine niddle aspiration cytology (FNAC) from this scalp swelling showed metastatic follicular carcinoma of thyroid (Figure 1,2). Patient was thoroughly investigated for metastatic workup. Contrast Enhanced computed tomography (CECT) brain showed erosion of cranial vault over parietooccipital area (Figure 3). Contrast Enhanced CT neck showed enlarged right thyroid lobe with two hypo dense mass lesions with calcification. Contrast Enhanced CT thorax showed presence of soft tissue nodules of varying size diffusely in both the lung fields, suggestive of metastasis. There was also mediastinal lymph-adenopathy suggestive of metastatic involvement with widening of mediastinum and left shift of the heart. Contrast Enhanced CT abdomen showed destruction of right iliac bone with expansile soft tissue mass formation.

Further nuclear imaging studies were done: Thallium 201 whole body revealed that the viable malignant tissue in the skull lesion was present predominantly in the lateral area and the base of the lesion (Figure 4). $80-90 \%$ of the tumour was necrotic. No abnormal tracer uptake was seen in the normal brain parenchyma inferior to the base of tumour. This suggested that the massive tumour region in the skull was largely necrotic and avascular. Abnormal tissue, probably malignant was present in right lobe of thyroid. Focal abnormality was seen in right clavicular region with diffuse area in the right lung mostly lower zone and upper zone of left lung. 
A large photopenic mediastinal mass is noted, pushing the heart laterally. An abnormal, discrete focus of radiotracer accumulation is noted in the 6 th rib posteriorly and in right iliac bone in the $3 \mathrm{hrs}$ image of the Tc-99m MDP Three phase bone scan (Figure 5).

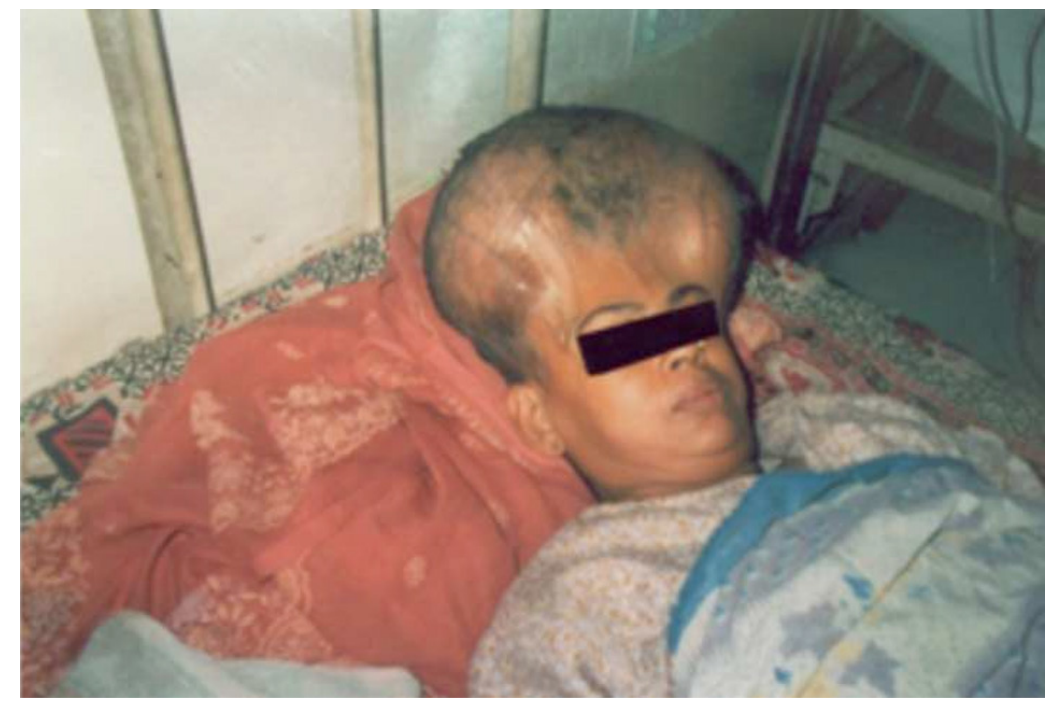

Figure 1: Photograph of patient showing huge scalp swelling

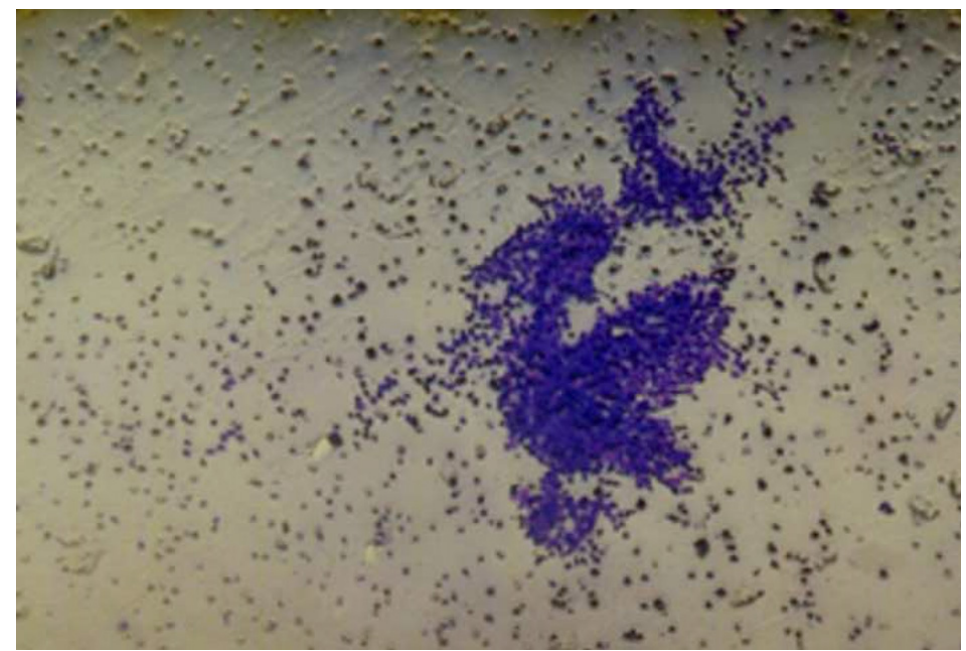

Figure 2: FNAC of scalp swelling showing metastatic follicular carcinoma of the thyroid (Zeimsa stain)

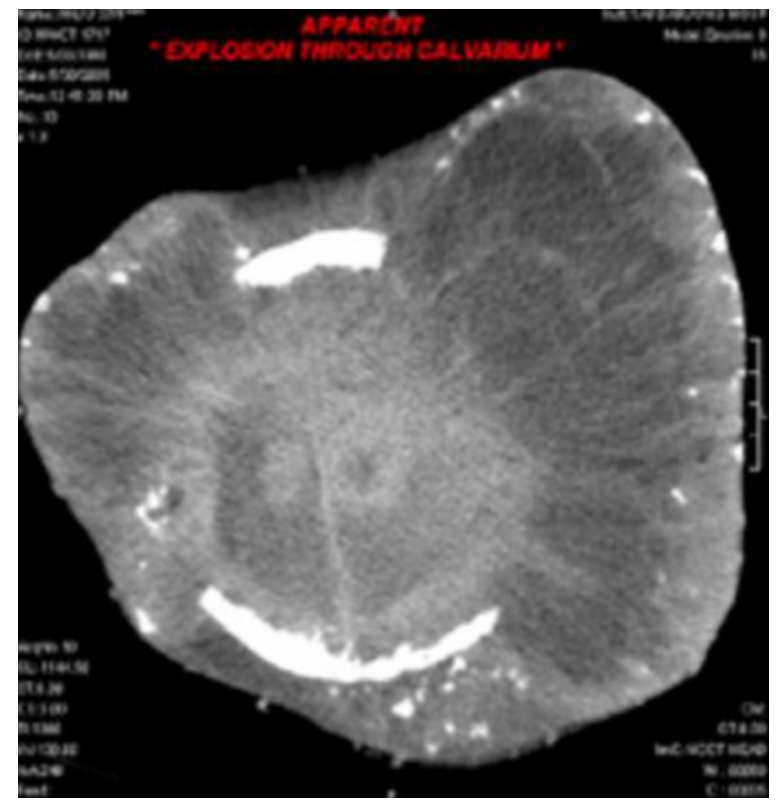

Figure 3: CECT brain showing erosion of cranial vault with homogenous mass 


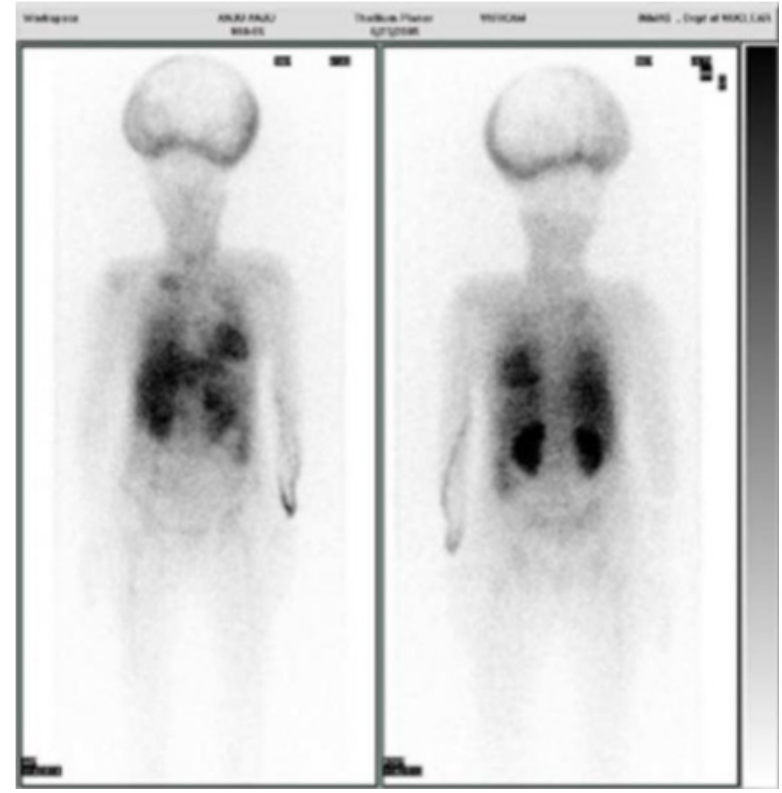

Figure 4: Thallium 201 whole body showing viable malignant tissue in the skull lesion is present predominantly in the lateral area and the base of the tumour

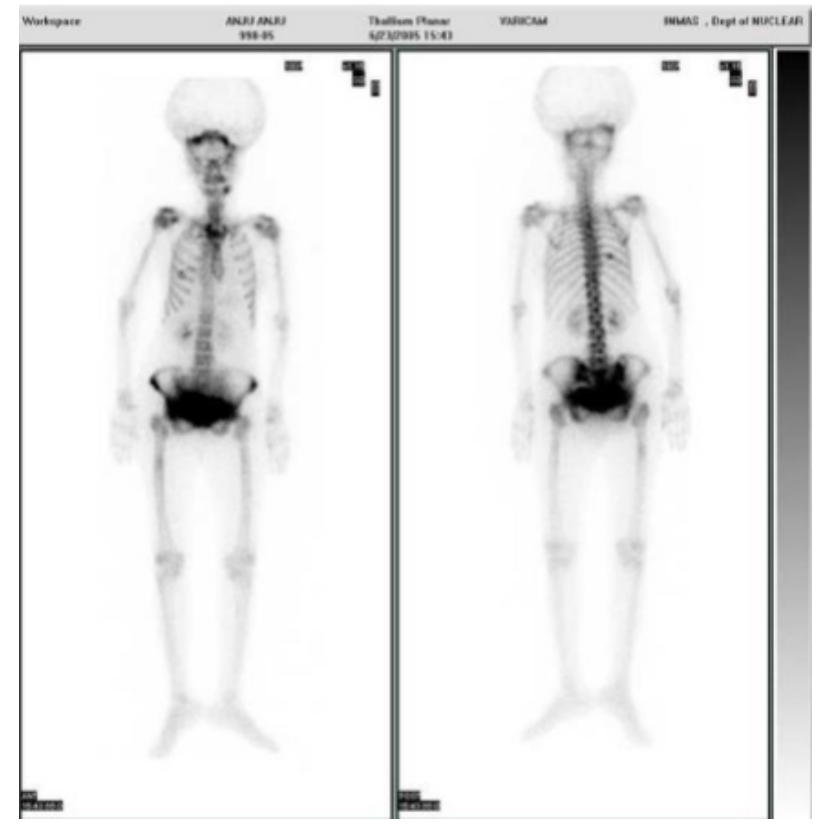

Figure 5: Technetium-99m MDP three-phase bones scan showing discrete uptake in $6^{\text {th }}$ rib and right iliac bone

After all the work up patient was diagnosed a case of follicular thyroid carcinoma with skull, scalp lung and bone secondaries. Patient was offered for subtotal thyroidectomy and debunking surgery of head, but patient denied for any surgical treatment. Radioiodine ablation treatment was not offered due to avascularity of tumour. So patient received 2 cycles of Palliative chemotherapy in the form of combination regimen consisting of Cyclophosphamide, Doxorubicin and Cisplatin. Patient showed good response after 1 cycle of chemotherapy but after second cycle of chemotherapy patient condition worsened and was kept on best palliative care only. Lastly patient died due to sudden cardio-pulmonary arrest after 3 months of diagnosis.

\section{Discussion}

Follicular thyroid carcinoma usually has a benign clinical course with an excellent long term prognosis and a propensity for vascular invasion. The most common sites of distant metastasis are lung, bones and lymph nodes. Generally this is not an aggressive tumour with 10 -years survival as high as $80-95 \%$. However the 10 -years survival rate in cases with distant metastasis decrease to around $40 \%[3,4]$. Bone metastasis of thyroid carcinoma is the second most common form of metastasis after lung metastasis [5,6]. The incidence of skull metastasis varies from 2.5-5.8\% [7,8] and is associated with mean survival rate of 4.5 years and 3.1 years respectively. In the large series of Mc Cormac, the incidence of bone metastasis is $12.7 \%$ but skull metastasis is rare [7]. In 1985, Nagamine et al. also reported a series of 12 cases (2.5\%) of skull metastasis among 473 cases of thyroid carcinoma [8]. The average 
age of patients with skull metastasis from thyroid carcinoma is around 60 years, with a female preponderance [8,9]. The usual presenting sign is a soft, painless scalp mass that is hemispheric in shape and that arises on the convexity of the skull. The lesion is usually singular but can be multiple. The lesion can be pulsatile and extremely vascular. The metastatic mass may invade the epidural space but the dura forms a barrier to further intracranial spread [9]. Most of these tumours are located in the posterior portion of the cranium and fed primarily from the external carotid artery system [8-11]. Progression of these lesions is generally very slow and mean survival period from the definitive diagnosis of skull metastasis is about 4-5 years [8,9 and 12]. Previously Skin metastases have not been widely reported among the largest series in literature $[1,13,14]$.

Boehm et al. published a report on 28-year-old woman with follicular thyroid carcinoma and a single left occipital lytic lesion without subcutaneous metastasis. Other large study groups like those of Woolner et al. (0\698patients), Fiazell and Foote described 1 patient (1/393) with suspected skull $\backslash$ brain metastasis with cutaneous metastasis [13,14]. Ibanez et al. reported one case with skull lesion and scalp metastasis of papillary carcinoma [15]. Gates suggested that the apparent predilection for the scalp could be due to the vascularity and relative immobility of the skin at this site [16]. The metastatic pathway may be consistent with hematogenous dissemination 17 via the external carotid artery system [1]. The overall rarity of cutaneous metastasis from follicular thyroid carcinoma is reflected by presence of only 10 such cases previously reported in English language literature (Table 1): It has been noted that skin metastasis from malignant tumours generally indicated a poor prognosis and the patients usually die with in 3-6 months. However, rare cases of skin metastasis from thyroid carcinoma with relatively prolonged survival have been recorded despite the presence of other metastasis [17]. Ghfir I et al. published a case report where a follicular thyroid carcinoma metastasized to unusual skin locations in a 82-year-old woman who followed after a total thyroidectomy for follicular thyroid carcinoma [18]. Assessment after 2 years showed the presence of a small cervical residue, pulmonary metastases, and a high thyroglobulin level. Two sets of internal radiation therapy with iodine 131 (100 mCi each) followed. Response to treatment was poor, and cutaneous and subcutaneous nodules appeared on the abdomen, back, and front left thigh. Biopsy of these lesions showed that they were malignant, and testing with anti-thyroglobulin antibodies confirmed the diagnosis of cutaneous metastasis of follicular thyroid carcinoma. Ali Alkan reported a case of 57 year old female with a 7 years history of ischemic heart disease who presented with $4 \mathrm{~cm}$ thyroid mass with compressive symptoms [19]. Diagnostic workup revealed a follicular Thyroid Carcinoma and thyroidectomy was performed. With post surgical radioactive iodine therapy (RIT), patient was treated with l-thyroxine replacement. Two year after surgery, metastatic lesions in the lungs were detected and patient was followed with RIT. With progression after 2 courses of RIT, patient was for palliative chemotherapy but the comorbidity and the performance status were not suitable for cytotoxic therapy. Sorafenib was planned for palliative intent. Asad Jehangir et al. reported a 65-year-old Caucasian woman with a history of thyroid nodule presented with the complaint of rapidly growing skull nodules which had been present for 3 years but were stable [20]. The prognosis is relatively poor in metastatic follicular thyroid carcinoma with 5 and 10 years mortality rates of approximately $60 \%$ and $80 \%$ respectively [10]. Nagamine et al. reported in his series of 12 patients, a mean survival time of 4 years and 5 months from the time of definitive diagnosis of skull metastasis from thyroid carcinoma [8]. A few other reports have indicated however a favorable long term survival in patients younger than 45 years and especially in children.

\begin{tabular}{|c|c|c|c|c|c|c|}
\hline SN & Author (s) & $\begin{array}{c}\text { No of } \\
\text { Cases }\end{array}$ & Age/Sex & Lesion location & $\begin{array}{c}\text { Interval between } \\
\text { diagnosis of primary } \\
\text { and metastasis }\end{array}$ & $\begin{array}{c}\text { Status of last } \\
\text { follow-up }\end{array}$ \\
\hline 1 & Auty19 & 1 & $\mathrm{M} / 41$ & $\begin{array}{c}\text { Scalp, Face, } \\
\text { Neck, Thorax }\end{array}$ & 2 Years & NA \\
\hline 2 & Hamiltor20 & 1 & $\mathrm{M} / 56$ & Back thigh, Arm & 3 Years & NA \\
\hline 3 & Rico \&Penneys21 & 1 & $\mathrm{M} / 78$ & Cheek & NA & NA \\
\hline 4 & Pavlidis et al18 & 1 & $\begin{array}{c}\mathrm{M} / 85 \\
\text { F/55 }\end{array}$ & $\begin{array}{c}\text { Scalp } \\
\text { Scalp }\end{array}$ & $\begin{array}{c}8 \text { Years } \\
\text { Scalp }\end{array}$ & $\begin{array}{c}\text { Died 2 months later } \\
\text { NA }\end{array}$ \\
\hline 5 & Tronnrer et al22 & 1 & F/66 & Year & NA \\
\hline 6 & Vives et al23 & 1 & F/71 & Scalp & Y Years & $\begin{array}{c}\text { Alive 1 year later with } \\
\text { residual disease }\end{array}$ \\
\hline 7 & Caron et al24 & 1 & M/66 & Scalp & Died 3.6 years later \\
\hline 8 & Ruiz de Erenchua & 1 & F/57 & Scalp & Years & $\begin{array}{c}\text { Alive 1 year later with } \\
\text { residual disease }\end{array}$ \\
\hline 9 & Toyota et al26 & 1 & M/72 & Scalp & 1 Year & $\begin{array}{c}\text { Alive 1.6 years later } \\
\text { with no e/o disease }\end{array}$ \\
\hline 10 & Perikala V. Kumar & 1 & M/68 & Scalp & NA & NA \\
\hline
\end{tabular}

Table 1: Details of cases of cutaneous metastasis from follicular thyroid carcinoma since 1964

\section{Conclusion}

Bone and lung are the common sites of metastasis from Follicular Thyroid Carcinoma but involvement of skull is unusual, especially as the presenting feature. Cases of neglected or untreated follicular thyroid carcinoma can give rise to subcutaneous 
nodule of scalp and can also directly invade the underlying bone to produced lytic lesions; which must be differentiated from other tumours producing lytic lesion. Although the rare cutaneous metastases of follicular thyroid carcinoma usually occur on the scalp, firm nodular cutaneous lesions that are painless and resist standard treatment in patients with a history of thyroid cancer should suggest the possibility of metastasis. Metastases from Follicular Thyroid Carcinoma should be included in the differential of patients with new oteolytic hypervascular skull lesions or cutaneous lesions in head and neck area.

\section{References}

1. Mazzaferri EL (1981) Papillary and follicular thyroid cancer; a selective approach to diagnosis and treatment. Annu Rev Med 32: 73-91.

2. Simpson WJ, Mckinney SE, Carruthers JS et al. (1987) Papillary and follicular thyroid cancer. Am J Med 83: 479 -88.

3. Samaan NA, Schultz PN, Hichey RC, Goepfert H, Haynie TP et al. (1992) The results of various modalities of treatment of well differentiated thyroid carcinoma; A retrospective review of 1599 patients. J clin Endocrinol Metab 75: 714-20.

4. Schlumberger MJ (1998) Papillary and follicular thyroid carcinoma. N Engl J Med 338: 297-306.

5. Dinsmore RS, Hicken NF (1934) Metastases from malignant tumor of the thyroid: A study of 124 cases. Am J Surg 24: 202-4.

6. Mizukami Y, Michigishi T, Nomomura A, Hashimoto T, Terahata S et al. (1990) Distant metastases in differentiated thyroid carcinomas a clinical and pathological study. Hum Pathol 21: 283-90.

7. Mc Cormack KR (1966) Bone metastases from thyroid carcinoma. Cancer 19: 181-4.

8. Nagamine Y, Suzuki J, Katakaru R, Yoshimoto T, Metora N et al. (1985) Skull metastasis of thyroid carcinoma J Neuro Surg 63: 526-31.

9. Passerini A, Bertazoli (1965) A Cranial and Vertebral metastases from thyroid tumours and from benign metastasing goiters. Acta Neurol Scandinav 41: 419-30.

10. Boehm T, Rothouse L, wartofsky L, (1976) Metastatic occult follicular thyroid carcinoma. JAMA 235: 2420-1

11. Kearns DB, Robinson LD, Wright GL, WickerSham JK, Parke RB Jr (1988) Skull metastasesfrom follicular thyroid carcinoma. Arch otolaryngol head neck surg 114: 454-6.

12. Turner O, Germer WJ (1941) Metastases in the skull from carcinoma of the thyroid.Surgery 9: 403-14.

13. Woolner L, Beachrs O, Black M, Mc Conahey W, Keating R (1961) classification of prognosis of thyroid carcinoma. Am J Surg 102: $354-87$.

14. Frazell EL, Foote FW (1958) Papillary cancer of the thyroid. a review of 25 years of experience. Cancer 11: 895-922.

15. Ibanez ML, Russell WO, Albores-Saavedra J, Lampertico P, white EC et al. (1966) Thyroid carcinoma-Biologic behavior and mortality. Postmortem findings in 42 cases, including 27 in which the disease was fatal. Cancer 19: 1039-52.

16. Gates O (1937) Cutaneous metastases of malignant disease. Am J cancer 39: 718-30.

17. Pitlik S, Kitzes R, Ben- Bassat M, Rossenfield JB (1983) Thyroid carcinoma presenting as a solitary skin metastases. Cutis 31: 532-4.

18. Ghfir I, Ccedil Aoui M, Ben Rais N (2005) Follicular thyroid carcinoma: Metastasis to unusual skin locations. Presse Med 34: 1145-6.

19. Alkan A, Aksoy Altınboğa A, Mızrak D, Köksoy EB, Karcı E et al. (2016) Thyroid follicular carcinoma complicating with skin metastasis. J Oncolog Sci 2: 82-3.

20. Asad Jehangir, Ranjan Pathak, Madan Aryal, Anam Quereshi (2015) Thyroid follicular carcinoma presenting as metastatic skin nodules. 5: 10.3402/jchimp. v5.26332. 